\title{
Reflexões sobre as relações entre geodiversidade e patrimônio: um estudo de caso
}

\author{
Reflexiones sobre las relaciones entre geodiversidad y \\ patrimonio: un estudio de caso
}

Reflections on relations between geodiversity and heritage: a
case study

\author{
Aline Rocha de Souza Ferreira de Castro \\ aline@geologia.ufrj.br \\ Museu da Geodiversidade, IGEO/UFRJ, Rio de Janeiro, RJ \\ Kátia Leite Mansur \\ katia@geologia.ufrj.br \\ Universidade Federal do Rio de Janeiro, UFRJ \\ Ismar de Souza Carvalho \\ ismar@geologia.ufrj.br \\ Universidade Federal do Rio de Janeiro, UFRJ
}

Resumo: Santana do Cariri, no Ceará, demonstrou ser um caso apropriado para discussão sobre as relações existentes entre geodiversidade e patrimônio, através de uma abordagem mais integral, onde é considerada a percepção da população sobre a riqueza geológica local. As reflexões feitas a partir desta análise permitiram subsidiar uma abordagem conceitual que deu origem a uma proposta de definição para o termo patrimônio geológico. Conhecer a realidade e considerar as tradições dos locais tornam-se essenciais para definir, divulgar e gerenciar conflitos que possam levar à perda patrimonial, fazendo a população se tornar parte integrante do processo que leva à geoconservação.

Palavras-chave: Patrimônio geológico, Conceito, Geopark Araripe, Santana do Cariri

Resumen: Santana do Cariri, en Ceará, ha demostrado ser un caso apropiado para discusión acerca de las relaciones existentes entre geodiversidad y patrimonio, a través de um abordaje más integral, donde se considera la percepción de la población acerca de la riqueza geológica local. Los análisis han permitido subsidiar un abordaje conceptual que ha dado origen a una propuesta de definición para el término patrimonio geológico. Conocer la realidad y considerar las tradiciones de los locales se hace esenciales para definir, divulgar y dirigir conflictos que puedan llevar a la pérdida patrimonial haciendo la población parte integrante del proceso que conduce a la geoconservación.

Palabras clave: Patrimonio geológico, Concepto, Geopark Araripe, Santana do Cariri.

Abstract: Santana do Cariri, at Ceará, has rose as an appropriated case for discussing the relations existing between geodiversity and heritage, through an integral approach, where it is considered the people's perception about their local geological richness. The analysis allowed supporting a conceptual approach that originate a 
proposal for defining the term geoheritage. It becomes essential to know the reality and consider the traditions of local people to define, promote, and manage conflicts that may lead to heritage loss, by integrating the population in the process that drives to geoconservation.

Key words: Geoheritage, Concept, Geopark Araripe, Santana do Cariri.

\section{INTRODUÇÃO}

A geodiversidade, tanto in situ quanto $e x$ situ, pode vir a ser classificada como patrimônio, dependendo se a ela é atribuído valor. Ao mesmo tempo, a maior parte da geodiversidade nunca será considerada patrimônio. Patrimônio é a exceção. É uma seleção refinada, feita por especialistas indicados pela sociedade e deve receber condições técnicas e financeiras para se manter conservado e acessível, especialmente se foi legitimado pelo Estado.

Os significados que envolvem a palavra patrimônio são muito amplos e podem ser até contraditórios, pois a sociedade é múltipla e os especialistas que lidam com os diversos tipos de patrimônio são múltiplos também. Ademais, como esse conceito é fruto da apropriação dos valores pela sociedade, ela pode e deve fazer parte do processo de seleção e nomeação do patrimônio para se sentir representada. Assim, é necessário observar como o processo de indicação de um patrimônio ocorre na sociedade (CASTRO, 2017; CASTRO; MANSUR; CARVALHO, 2015; SOUZA, 2008).

Este artigo pretende discutir os conceitos de Geodiversidade e Patrimônio a ela associados e para tanto foi tomada como base a realidade do município de Santana do Cariri e seu entorno, no sul do estado do Ceará, selecionado pela riqueza (quantidade) e relevância (qualidade) da geodiversidade existente. A área selecionada concentra pelo menos quatro locais de interesse geológico significativo, todos integrantes do Geopark Araripe: (1) o geossítio Pontal da Santa Cruz; (2) o geossítio Parque dos Pterossauros; (3) o geossítio Pedra Cariri; e (4) o Museu de Paleontologia de Santana do Cariri, da Universidade Regional do Cariri (URCA), além de diversos locais de exploração econômica de calcário laminado e gipsita.

A região é rica em diversidade geológica e com abundância de fósseis, bem preservados e diversificados, tornando-a o destino de geocientistas de todo o mundo (VIANA, 2001; ARAI; COIMBRA, 1990; BRUNO; HESSEL, 2006; CARVALHO; MELO, 2012; CARVALHO; SANTOS, 2005; MARTILL; BECHLY; LOVERIDGE, 2007; MOURA; BARRETO; BÁEZ, 2006; SANTOS, 1991; VIANA; NEUMANN, 2002). Por ser parte do Geopark Araripe, espera-se ampla visitação de turistas, inclusive do exterior, que proporcione o desenvolvimento local pela vertente do Geoturismo. Por outro lado, a região não oferece muitas oportunidades de trabalho e condições de estudo, situação que provoca a emigração dos mais jovens, que se dirigem para as cidades maiores em busca de melhores condições de vida. Essa contradição torna a região exemplar para a discussão conceitual sobre as 
relações existentes entre a Geodiversidade e o Patrimônio, considerando a perspectiva da população residente no entorno dos geossítios.

\section{UM PROCESSO INVERTIDO?}

Denominar a geodiversidade como patrimônio foi um processo de amadurecimento que envolveu a própria compreensão do que é patrimônio. A Convenção para a Proteção do Patrimônio Mundial, Natural e Cultural da UNESCO, de 1972, inovou, na época, ao considerar na categoria de patrimônio mundial tanto a vertente natural quanto cultural (ICOM, 1999; UNESCO, 1972). Para as discussões que aconteceram na década de 1970, tornava-se quase imperativo a necessidade de incluir a natureza nesse processo preservacionista e patrimonial.

Porém, existem duas considerações importantes a serem feitas.

A primeira diz respeito à própria concepção de patrimônio e a visão de mundo de cada sociedade. Dependendo da percepção do que é natureza e do que é cultura, essa diferenciação de nomenclaturas perde o sentido e um conceito pode englobar o outro (CANCLINI, 1998; CARVALHO, 1999; ZANIRATO; RIBEIRO, 2006; PAES-LUCHIARI, BRUHNS; SERRANO, 2007).

A segunda consideração envolve a percepção de que as discussões realizadas na década de 1970 obtiveram êxito em incluir a natureza como patrimônio. No entanto, com o passar do tempo e ao se avaliar como o processo de desenrolou, foi possível perceber que uma parte da natureza foi mais contemplada do que outra. Nesse processo, incentivou-se a proteção da biodiversidade, mas a geodiversidade, embora fosse mencionada na convenção, não recebeu a mesma atenção (ver algumas discussões em GORDON; LEYS, 2001; GRAY, 2004, 2013, entre outros).

A origem do conceito de geoparques também reflete essa evolução conceitual histórica. Ele surgiu no final do Século XX com o reconhecimento da dificuldade de gestão dos parques geológicos nacionais com os meios então disponíveis numa Europa em crise. Modica (2009) apresenta o quadro da época, considerando os quatro parques geológicos que se uniram para enfrentar a situação:

Os quatro territórios tinham características naturais e sócio-econômicas comuns: sítios geológicos de grande relevância científica e estética, cujo potencial não havia sido descoberto ou apreciado, falta de desenvolvimento econômico, elevada taxa de desemprego, migração e abandono da área por parte da população jovem (MODICA, 2009, p. 2).

Associado ao movimento ambientalista que vem desde a década de 1970 e marcado pela Convenção de Paris ocorrida em 1972, também cresceu na comunidade geocientífica a percepção de que a distância e o desconhecimento dos conceitos relacionados à Geologia por parte da sociedade era prejudicial à conservação da geodiversidade. Reconhecer a geodiversidade como patrimônio foi um dos caminhos naturais para incentivar a sua 
divulgação. Passou a ser estratégico fazer com que a sociedade como um todo compreendesse o quanto as rochas, os fósseis, os minerais, as paisagens e os processos associados são relevantes.

Com a intensificação da percepção do valor patrimonial, ações educativas foram realizadas em maior quantidade e intensidade e a educação não formal em Geociências ganhou força, assim como a luta por mais espaço na educação formal. Todo esse esforço parece apontar para uma ação que busca evitar que a falta de conhecimento sobre a relevância da geodiversidade, para a memória e o desenvolvimento de nossa sociedade, resultasse na perda e na depredação deste tipo de patrimônio natural não renovável.

Esse movimento se desenvolveu por todo o mundo, em especial no Reino Unido, na Austrália, em Portugal e na Espanha. Quando chegou ao Brasil, o termo Patrimônio Geológico se firmou no meio acadêmico quase 'pronto'. Na perspectiva de avançar na mesma direção e velocidade dos países onde a discussão estava mais avançada, acredita-se que faltou tempo para amadurecer os conceitos de Patrimônio Geológico e Geoconservação sob a ótica de um país como o Brasil, com todas as implicações territoriais, sociopolíticas e econômicas que advém de uma conformação quase continental em um país mantido coeso pelo colonialismo português, seguido de um império sob comando da mesma família real, e por uma república dirigida por uma elite sobrevivente das etapas anteriores.

É possível afirmar que essa atribuição de valor patrimonial ainda precisa ser mais debatida teoricamente entre os pares. Tais reflexões podem vir a se consolidar em um campo do saber que trata das relações entre a geodiversidade e o patrimônio, resultando na ampliação dos conceitos de Patrimônio Geológico e Geoconservação, ao considerar também a percepção da sociedade.

\section{COMO SURGEM OS CONCEITOS?}

\section{Patrimônio}

A origem do conceito Patrimônio ainda é muito discutida na literatura. A compreensão do patrimônio como uma herança, como algo recebido por direito, é registrada desde o Direito Romano (LIMA, 1997). Muito tempo depois, a noção de patrimônio, já modificada, passou a englobar também os bens imóveis representativos, cuja arquitetura se destacasse artisticamente, e para as esculturas e pinturas (CHOAY, 2001).

Patrimônio também está relacionado a poder. Ao longo da história humana, foi associado a marcos ideológicos ou utilizado para legitimar algum fator político, como no final século XVIIII, com a Revolução Francesa. De acordo com Babelon e Chastel (1994), nesse momento surgiu a concepção moderna de patrimônio. As noções de patrimônio, na França, país europeu com desenvolvimento organizacional distinto do Brasil, revelaram diferentes significados de acordo com o momento histórico, embora o sentido atual da palavra indique algo relacionado com bens e tesouros herdados do passado. 
Por essa breve exposição, é possível perceber o quanto o conceito de patrimônio é polissêmico - ao longo do tempo assumiu e assume vários significados ainda hoje, tais como herança, bens (móveis e imóveis) e monumento, com possibilidade de se apresentar através de elementos tangíveis (materiais) ou intangíveis (imateriais), de acordo com a sociedade na qual esses elementos estão inseridos. Isso é uma maneira de afirmar que um patrimônio é o reflexo daquilo que uma sociedade valoriza (SCHEINER, 2004; LIMA; COSTA, 2007; CHAGAS, 2007; CASTRO, 2014, 2017).

Um elemento qualificado como patrimônio sofreu uma atribuição de valor que o destacou e o diferenciou perante os demais de sua espécie/tipologia (LIMA, 1997). Logo, é reflexo do que a sociedade considera relevante e, por isso, deseja conservar a sua integridade física (ou registrá-lo, no caso dos intangíveis) para que possa ser contemplado por mais pessoas e por mais tempo. Esse desejo é reflexo da incessante busca de permanência no mundo que, como não pode ser alcançado pelo ser humano, justamente pela finitude de sua vida, é canalizado para as coisas, ou seja,

(...) se o desejo de eternidade está na origem da experiência humana da temporalidade, é na relação entre a percepção do efêmero e o desejo do eterno que poderemos reconhecer as articulações de pensamento que teriam dado origem à ideia de patrimônio (SCHEINER, 2004, p.37).

Intrinsecamente relacionados a essa relação conflituosa do ser humano com o tempo está a geodiversidade, cujas nuances só podem ser compreendidas com a assimilação do conceito de Tempo Profundo ou de Tempo Geológico. É um desafio para o ser humano tentar compreender os produtos de fenômenos e processos que não podem ser observados na escala de tempo de sua vida, de sua referência. O conflito entre a percepção do efêmero e o desejo do eterno está presente nesta relação de forma profunda e indelével.

Objectos naturais bastante inquietantes estes fósseis! Impuseram-se quase de repente à percepção dos homens, inserindo-se à força nos seus sistemas de representação; em seguida, obrigaram-nos a interrogar-se sobre a história do seu universo e logo a pôr em causa alguns dos seus mitos, ainda que, por vezes e por um certo período, parecessem confirmar-lhes os fundamentos. Com uma espécie de interface situada entre o inanimado e o animado, estes fósseis levariam os homens a reflectir sobre a antiguidade do seu planeta, sobre a origem da vida nele e a descobrir as sucessivas transformações da natureza viva. (...) Poucos outros objetos naturais alimentaram no pensamento humano tanto o sonho como a razão (BARRAU, 1984, p. 89).

Não se pode refletir sobre o conceito de patrimônio sem inserir a relevância da atribuição de valor. E como algo de valor, é também signo, integrado às noções de identidade e de pertencimento de um grupo social. Esse sentimento de pertencimento e de apropriação por um grupo social faz com que um elemento considerado como patrimônio seja representante da identidade coletiva.

O próprio conceito de Patrimônio remete à ideia de valor, o que nos permite lembrar o seu caráter de signo. Lembremos aqui, mais uma vez, que o Patrimônio 
é uma poderosa construção sígnica, constituída e instituída a partir de percepções identitárias e integralmente vinculada ao sentimento de pertença - a partir do qual se reflete em todos os jogos da memória e se expressa em todas as representações sociais. (...) Impregnado de um sentido econômico, expressa as relações que cada grupo social estabelece com a natureza ou com sua produção cultural - estando diretamente influenciado pelas maneiras sob as quais cada sociedade compreende Natureza e Cultura (SCHEINER, 2006, p.05).

É importante reconhecer que cada sociedade (ou comunidade) pode compreender natureza e cultura de formas distintas e o modo como isso acontece pode estar associado a questões econômicas, políticas e ideológicas. Esses não são aspectos necessariamente ruins ou bons, mas é preciso reconhecer essa possibilidade, pois isso também influenciará na compreensão do que é patrimônio e o modo como a sociedade se apropriará dele.

Assim, de acordo com a etimologia da palavra o patrimônio é algo herdado. Sobre isso, Gonçalves (2002) reflete que quando se herda alguma coisa, o que é adquirido não é, necessariamente, desejado. Assim, para que algum elemento seja reconhecido como patrimônio, deve ser apropriado ${ }^{1}$ por algum grupo social. Só assim, ele será legitimado e a sua preservação será reivindicada.

Apropriar-se é sinônimo de preservação e definição de uma identidade, o que significa dizer, no plano das narrativas nacionais, que uma nação torna-se o que ela é na medida em que se apropria do seu Patrimônio (GONÇALVES, 2002, p.24).

Em meio a tudo o que foi mencionado, talvez o caminho a ser trilhado envolva a percepção do patrimônio em seu sentido integral. Sem o recorte cartesiano que nos trouxe ao momento de separar e dividir as coisas em categorias, adjetivando-as. Além disso,

(...) percebeu-se que o uso do termo patrimônio, associado indiscriminadamente a múltiplos adjetivos - tais como natural, cultural, móvel, imóvel, tangível, intangível entre outros - dificultava o entendimento e a comunicação entre os profissionais de museus, transformando-se em uma confusão terminológica (CARVALHO; SCHEINER, 2010, p. 454).

Na verdade, o uso inapropriado do termo patrimônio dificulta a comunicação não apenas aos profissionais de museus, mas a todos que atuam na área patrimonial. Se os envolvidos não conseguirem dialogar entre si sem ruídos, também haverá dificuldade em se comunicar com o restante da sociedade. Além disso, deve-se haver esforço para acompanhar as mudanças sociais, políticas, econômicas e culturais das sociedades. Uma vez que se deve reconhecer que objetos/elementos considerados como patrimônio são "suportes físicos de valores intangíveis, sendo polissêmicos e com diferentes cargas simbólicas", incluindo a geodiversidade (CARVALHO; SCHEINER, 2010, p.454).

Com essas considerações, não se quer diminuir a importância dos aspectos científicos da geodiversidade, mas ressaltar que, ao ser considerada patrimônio, ela também passa

1 De acordo com o Dicionário Eletrônico Houaiss da Língua Portuguesa (2001) apropriar significa "tomar para si, tomar como propriedade; arrogar-se a posse de; apoderar(-se), assenhorear(-se)". 
a ser "suporte de valores imateriais oriundos dos significados espirituais [e simbólicos] atribuídos pelo homem, vinculados com sua identidade" (CARVALHO; SCHEINER, 2010, p.454). Compreender esses aspectos pode ser o caminho para se trabalhar com a geodiversidade em sua integralidade patrimonial.

\section{Geodiversidade}

O termo geodiversidade começou a ser usado na década de 1990, inserido em alguns trabalhos australianos (KIERNAN, 1991), mas foi formalizado na ocasião da Conferência de Malvern sobre a Conservação Geológica e Paisagística realizada no Reino Unido, em 1993 (GRAY, 2004, 2008, 2013; BRILHA, 2005; NASCIMENTO; RUCHKYS; MANTESSO NETO, 2008).

Na literatura, encontram-se diferentes definições sobre a geodiversidade, demonstrando que ainda busca-se um consenso para esse termo. São poucas as referências nacionais que trabalham o conceito de forma teórica (SOUZA; MIRANDA, 2007; SANTOS et al., 2017). Assim sendo, algumas das mais utilizadas para ilustrar essa complexidade, elaboradas por pesquisadores estrangeiros e aquela publicada pelo Serviço Geológico do Brasil - CPRM, são destacadas a seguir.

Geodiversity - of significant geological (bedrock), geomorphological (landform) and soil features and processes (SHARPLES, 2002, p. 2).

(...) the natural variety of the Earth's surface, referring to geological and geomorphological aspects, soils and surface waters as well as to other systems created as a result of both natural (endogenic and exogenic) processes and human activity (KOZLOWSKI, 2004, p. 834).

O estudo da natureza abiótica (meio físico) constituída por uma variedade de ambientes, composição, fenômenos e processos geológicos que dão origem às paisagens, rochas, minerais, águas, fósseis, solos, clima e outros depósitos superficiais que propiciam o desenvolvimento da vida na Terra, tendo como valores intrínsecos a cultura, o estético, o econômico, o científico, o educativo e o turístico (CPRM, 2006, p. 4).

The natural range (diversity) of geological (rocks, minerals, fossils), geomorphological (landforms, topography, physical processes), soil and hydrological features. It includes their assemblages, structures, systems and contributions to landscapes (GRAY, 2013. p. 12).

Geodiversity is the variety of geological environments, phenomena and active processes that make landscapes, rocks, minerals, fossils, soils and other superficial deposits which provide the framework for life on Earth (STANLEY, 2000, p. 15).

As definições ilustram como os conceitos são variados. As propostas de Sharples (2002) e de Stanley (2000) buscam ser abrangentes, mas não se comprometeram com especificações. Estão mais direcionadas para sistemas e processos, não enfatizando os produtos destes. Esta é uma tendência nas definições, embora Gray (2013) especifique, citando inclusive exemplares da diversidade geológica como os fósseis, os minerais, as 
rochas, os solos, a água e o relevo, e ainda contemple em sua definição o contexto em que o elemento foi encontrado (assembleias, relações e processos).

Gray (2013) concordou com a definição de Sharples (2002) e a aprimorou ao longo dos anos, fazendo com que sua proposta se destacasse em relação às demais. Kozlowski (2004) inclui, também, a atividade humana como capaz de gerar geodiversidade. Esta é uma posição que gera polêmica, mas que encontra abrigo em trabalhos como o de Hazen et al. (2017), que trata de minerais gerados por ações antropogênicas e reconhecidos pela International Mineralogical Association.

Também merece destaque a parte final da definição elaborada por Stanley (2000), quando membro da Royal Society for Nature Conservation (RSNC-UK), que enfatiza a importância da geodiversidade como suporte à vida na Terra.

Para atender aos objetivos da discussão em foco, é possível considerar que a geodiversidade consiste na variedade de minerais, fósseis, rochas e solos e água que ocorrem no Planeta Terra e que podem estar in situ ou ex situ, além de paisagens e processos associados. Os componentes in situ da geodiversidade são claramente identificados pelos geocientistas, conforme as definições apresentadas, mas ainda estão em processo de reconhecimento pela sociedade em geral, embora seja nítido o caso de paisagens turísticas (ex.: Pão de Açúcar), de cavernas (ex.: Maquiné) e os fósseis de dinossauros. Isto significa que já existem apropriações do valor da geodiversidade feitas pela sociedade.

\section{Patrimônio Geológico}

Geodiversidade não é sinônimo de patrimônio geológico. Implícito à atribuição de valor e à qualificação de patrimônio à geodiversidade está o ato da seleção. É necessário selecionar o que é relevante, atribuindo valor. De outra forma, todas as coisas se tornariam patrimônio, perdendo sentido o uso do termo, a diferenciação e o discurso por preservação. Portanto, patrimônio geológico é um sítio ou objeto da geodiversidade relevante, selecionado de acordo com alguns critérios para ser preservado e poder ser contemplado por mais tempo e por mais pessoas. Esses critérios podem ser variados e diversos, embora se perceba na literatura, nos casos já reconhecidos como patrimônio, que os critérios científicos, educacionais e turísticos são os mais utilizados.

Diferentes autores já publicaram definições de patrimônio geológico. Serão destacadas a seguir quatro definições.

Por Patrimonio Geológico se puede entender todas aquellas formaciones rocosas, estructuras, acumulaciones sedimentarias, formas, paisajes, yacimientos minerales o paleontológicos o colecciones de objetos geológicos de valor científico, cultural o educativo y/o de interés paisajístico o recreativo. También puede incluir los elementos de arqueología industrial relacionados con instalaciones para la explotación de recursos del medio geológico (UCEDA, 1996, p. 19).

[Patrimônio geológico corresponde ao] conjunto de geossítios (ou locais de interesse geológico) inventariados e caracterizados de uma dada região, sendo os geossítios 
locais bem delimitados geograficamente, onde ocorrem um ou mais elementos da geodiversidade com singular valor do ponto de vista científico, pedagógico, cultural, turístico ou outro (BRILHA, 2005, p.5).

Geological heritage, or geoheritage, refers to (i) in situ occurrences of geodiversity elements with high scientific value - geosites and (ii) ex situ geodiversity elements that, in spite of being displaced from their natural location of occurrence, maintain a high scientific value (for instance, minerals, fossils, and rocks available for research in museum collections) - geoheritage elements (BRILHA, 2016, p. 120).

Patrimônio geológico in situ corresponde ao conjunto de depósitos minerais ou fossilíferos (aflorantes ou não), paisagens e solos de uma determinada região, bem delimitados geograficamente, onde ocorrem elementos da geodiversidade com singular valor do ponto de vista científico, didático, cultural, estético, entre outros (PONCIANO et al., 2011, p. 855).

Nas definições encontradas na literatura é possível perceber que o local onde a geodiversidade está preservada, se é in situ ou ex situ, determina a sua condição como patrimônio geológico. Alguns autores não consideram como Patrimônio Geológico a geodiversidade preservada ex situ, como as coleções salvaguardadas pelos museus, embora reconheçam que possuam valor.

Outro ponto a ser comentado refere-se aos valores. Considera-se como patrimônio geológico a geodiversidade que possui (ou é atribuído a ela) algum valor, seja científico, cultural, recreativo ou interesse paisagístico. Está presente a valorização sob o cunho científico ou cultural, o que corrobora as múltiplas facetas patrimoniais da geodiversidade. No entanto, o cunho científico é o mais presente dos critérios propostos para defini-lo. Os outros valores mencionados são utilizados de forma genérica para completar o valor científico ou, mesmo, não são considerados conforme em Brilha (2016).

Vale destacar que com o passar do tempo o entendimento de Brilha (2005) se modificou. Em 2005 os demais valores eram contemplados, mas em 2016, o patrimônio geológico foi compreendido apenas aquela geodiversidade in situ ou ex situ que tenha valor científico (BRILHA, 2005; 2016). O autor ainda considera que a geodiversidade com valor turístico e educativo também deva ser objeto da Geoconservação, mas não são denominados por ele como Patrimônio Geológico. O mesmo verifica-se em muitas metodologias de avaliação utilizadas para atribuir relevância aos sítios. Critérios científicos, educativos, turísticos, paisagísticos são utilizados como, por exemplo, por García-Cortés e Carcavilla (2009), Uceda (1996; 2000), Brilha (2016), Carcavilla et al. (2007) e Pereira (2006). Assim, é preciso considerar que os aspectos científicos contemplam apenas uma parte de muitos outros significados que podem ser atribuídos à geodiversidade.

Diversos exemplos desses significados podem ser encontrados nos nomes de cidades e de montanhas, em especial, nas denominadas geoformas, esculpidas por processos erosivos, em histórias e lendas locais, em esculturas artísticas feitas com rochas variadas, em artesanatos, entre outros.

Em Santana do Cariri também se verifica outras formas de apropriação, onde a população reconhece os fósseis e lhes atribuiu nomes específicos. Na pesquisa realizada 
por Castro (2014), verificou-se o uso de expressões como pedra de peixe, espadarte, larva, curimatã, pé de pau, piabinha, borboleta, lagartixa, grilo, arraia, jacaré, zig-zig e besouro para nomear os fósseis. Ou seja, a população conhece aqueles fósseis para além do discurso 'oficial'².

Enfim, são múltiplas as possibilidades, mas elas não podem deixar de ser contempladas apenas porque não foram geradas no meio científico. Essas premissas também podem ser usadas quando se atribuí valor patrimonial à geodiversidade. A inserção dos valores culturais, próprios de cada comunidade, amplia as discussões a respeito desta temática e ilustra que outros especialistas de diferentes áreas podem contribuir com suas visões, enriquecendo o significado do que se denominou patrimônio geológico.

O que é necessário entender é que cada indivíduo ou comunidade pode identificar, valorizar e nomear o que é o seu Patrimônio. Talvez a nossa função - como profissionais desta área - seria a de gerar subsídios para uma melhor compreensão, através de um conjunto de dispositivos que incluiria até mesmo os documentos produzidos pelo discurso oficial (CARVALHO; SCHEINER, 2010, p. 457).

Ao fazer o movimento em busca da atenção da população para os problemas, muitas vezes graves e urgentes, que a geodiversidade está sujeita, como o risco de destruição por motivos diversos, deve-se tentar uma aproximação mais sensível, baseada na possibilidade de trocas de conhecimentos diferentes sobre um mesmo elemento. A postura de detentor do conhecimento ainda está presente em muitos cientistas que, mesmo se aproximando da área patrimonial, agem como se a população não tivesse nenhum conhecimento sobre o assunto ou, no dizer de Massarani, Moreira e Brito (2002), é como se precisassem preencher um recipiente sem conteúdo, configurando um método de comunicação em ciência que é denominado de Modelo de Déficit (LEWEINTEIN, 2003; BROSSARD; LEWENSTEIN, 2010).

\section{O EXEMPLO DE SANTANA DO CARIRI, CEARÁ: UM DOS MUNICÍPIOS QUE INTEGRAM O GEOPARK ARARIPE}

Localizado no sul do Estado do Ceará, o Geopark Araripe faz parte da região denominada Cariri, que se destaca por suas paisagens verdes em meio ao semiárido do Nordeste brasileiro. Seu território abrange seis municípios ${ }^{3}$, totalizando um território de 3.796 km², com nove geossítios (BEZERRA et al., 2010; HERZOG; SALES; HILLMER, 2008).

2 Para aprofundamento sobre o discurso 'oficial' do patrimônio, ver Carvalho e Scheiner (2010) e Kunzler e Machado (2017).

3 Crato, Juazeiro do Norte, Barbalha, Missão Velha, Nova Olinda e Santana do Cariri. 
Figura 1: Localização geopolítica do município de Santana do Cariri, Ceará e da Bacia do Araripe

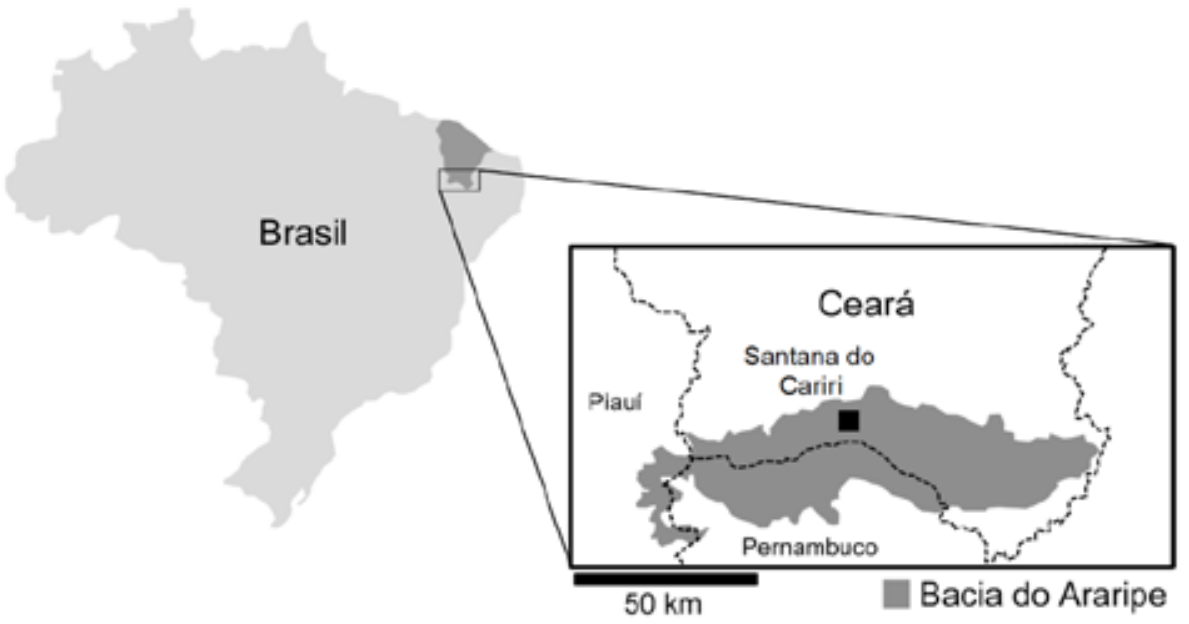

Fonte: Assine (2007).

Considerando o vasto território e as diversas possibilidades de estudo relacionadas ao patrimônio, o enfoque será dado ao município de Santana do Cariri, pois esse concentra em seu território e entorno três ${ }^{4}$ dos nove geossítios, além do Museu de Paleontologia de Santana do Cariri, da Universidade Regional do Cariri (URCA) e diversos locais de coletas de fósseis de onde vieram relevantes descobertas paleontológicas.

Figura 2: Geossítio Pedra Cariri, Geopark Araripe, localizado à margem da rodovia estadual CE-166 (2011).

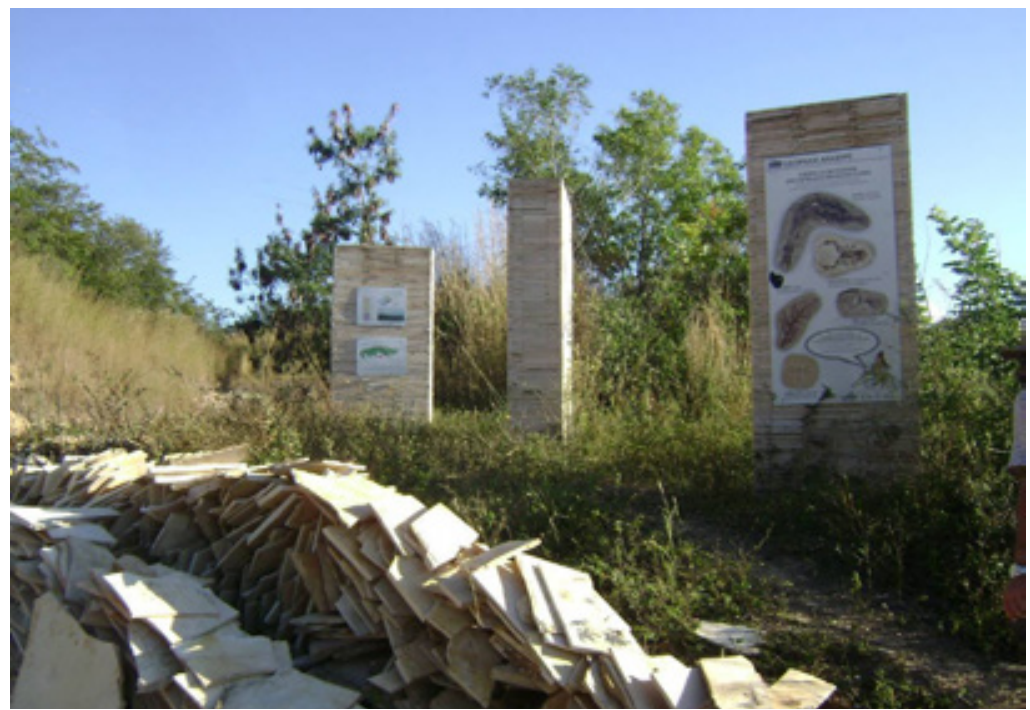

Fonte: os autores.

4 Embora o geossítio Pedra Cariri esteja territorialmente inserido no município de Nova Olinda, para os autores ele possui maior relação territorial com o município de Santana do Cariri, pois está mais próximo dele e se localiza às margens da rodovia que dá acesso à sede municipal. 
Figura 3: Geossítio Parque dos Pterossauros (2012).

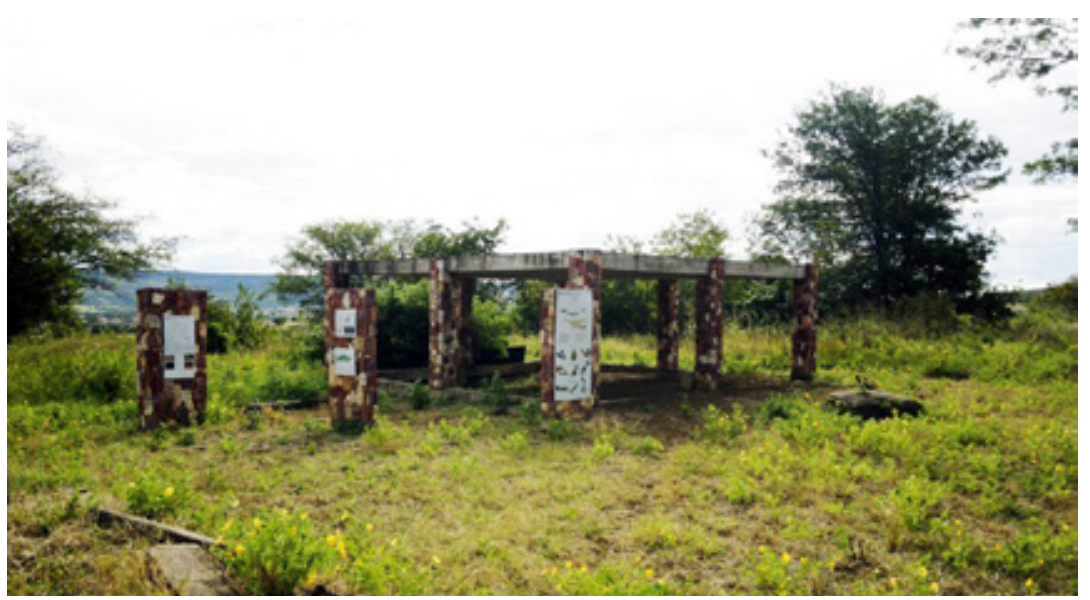

Fonte: os autores.

Figura 4: Acesso ao geossítio Pontal da Santa Cruz artavés da trilha. Ao fundo, a Chapada do Araripe (2012).

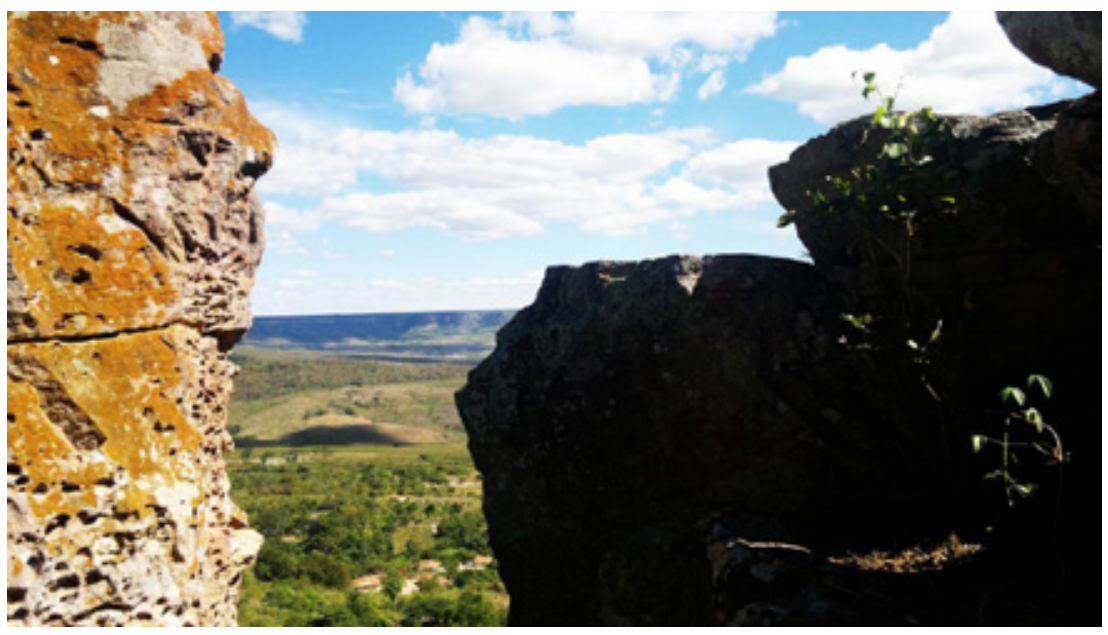

Fonte: os autores.

Figura 5: Geossítio Pontal da Santa Cruz. No primeiro plano, os arenitos da Formação Exu com a cruz, menor, em madeira. Ao fundo, a Chapada do Araripe (2012).

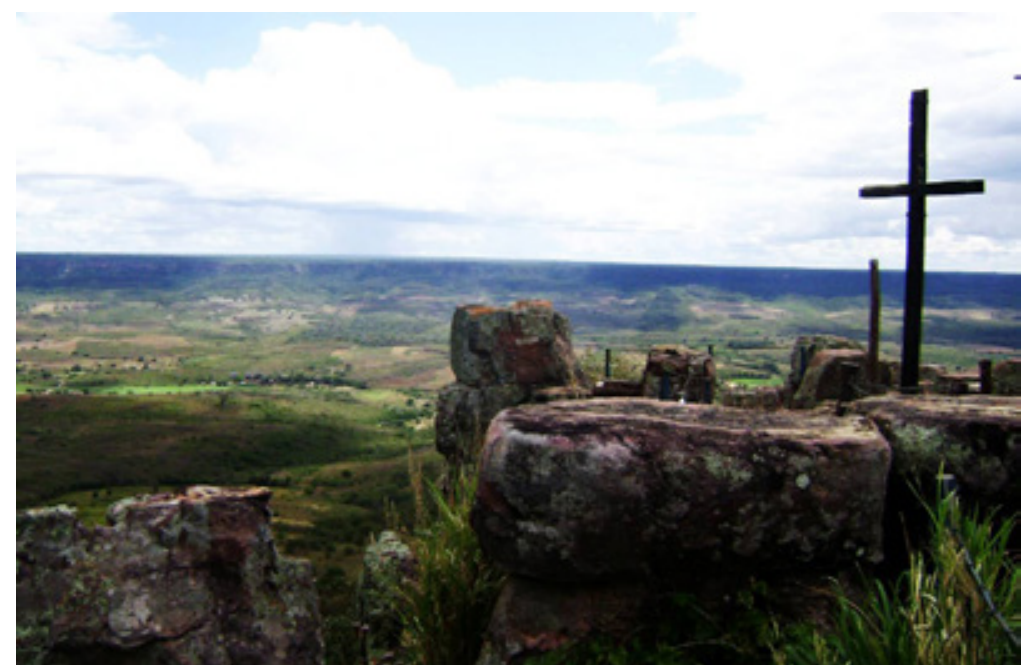

Fonte: os autores. 
Figura 6: Museu de Paleontologia de Santana do Cariri (2012).

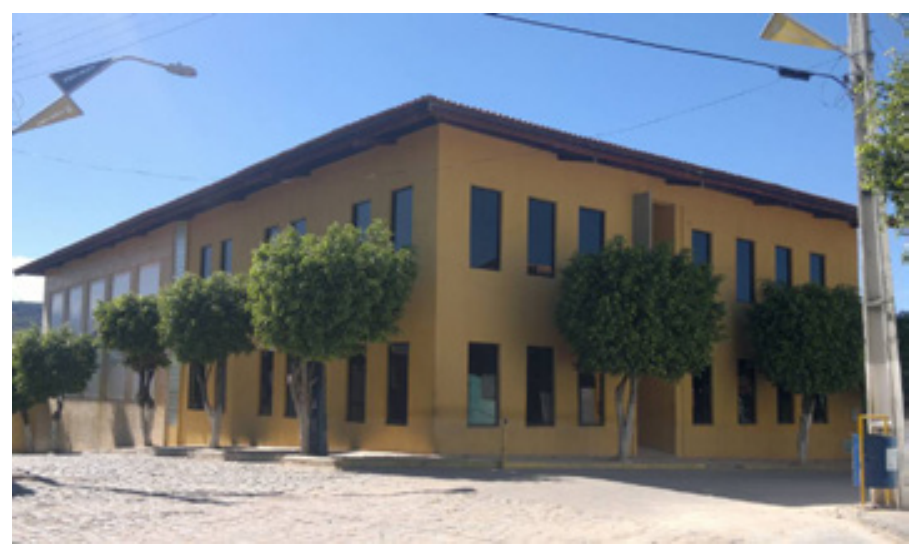

Fonte: os autores.

Os estudos paleontológicos revelam a grandeza da geodiversidade (biodiversidade preservada nas rochas), representada pelos fósseis da região. Nas últimas décadas do século XX e início do século XXI os estudos científicos demostraram a importância deste patrimônio de relevância internacional, fortalecendo os movimentos de proteção dos afloramentos paleontológicos. Esta proteção carrega em si uma grande contradição: como encontrar os fósseis sem alterar os afloramentos? Em alguns casos parece que a única solução é sua conservação ex situ, inclusive porque a pesquisa pelos fósseis pressupõe, de maneira geral, sua retirada do afloramento.

A geodiversidade presente nos fósseis da Bacia do Araripe representa um evento biológico único, caracterizado pelo surgimento de novos gêneros entre populações de insetos, peixes e répteis, e até mesmo de novas famílias, como ocorreu com os pterossauros. Havia um ambiente favorável à vida, que associado às condições especiais pós-morte, possibilitaram a preservação excepcional dos fósseis (VIANA; NEUMANN, 2002; CARVALHO; SANTOS, 2005; MARTILL; BECHLY; LOVERIDGE, 2007).

O termo Lagerstätten é atribuído aos jazigos fósseis que possuem uma conservação extraordinária. Este conceito é perfeitamente aplicado à Formação Santana, em seus dois membros: Crato e Romualdo (CARVALHO; SANTOS, 2005). No Membro Crato encontram-se algas, vegetais, artrópodes, moluscos, peixes, anfíbios, pterossauros e penas de aves e, no Membro Romualdo, há exemplares de vegetais, artrópodes, moluscos, equinóides, peixes, dinossauros terópodes e grande variedade de pterossauros (CARVALHO; SANTOS, 2005; MARTILL; BECHLY; LOVERIDGE, 2007). 
Figura 7: Imagens de alguns fósseis encontrados na região (Formação Santana, Bacia do Araripe), ilustrando a abundância e a diversidade de peixes encontrados (2012).

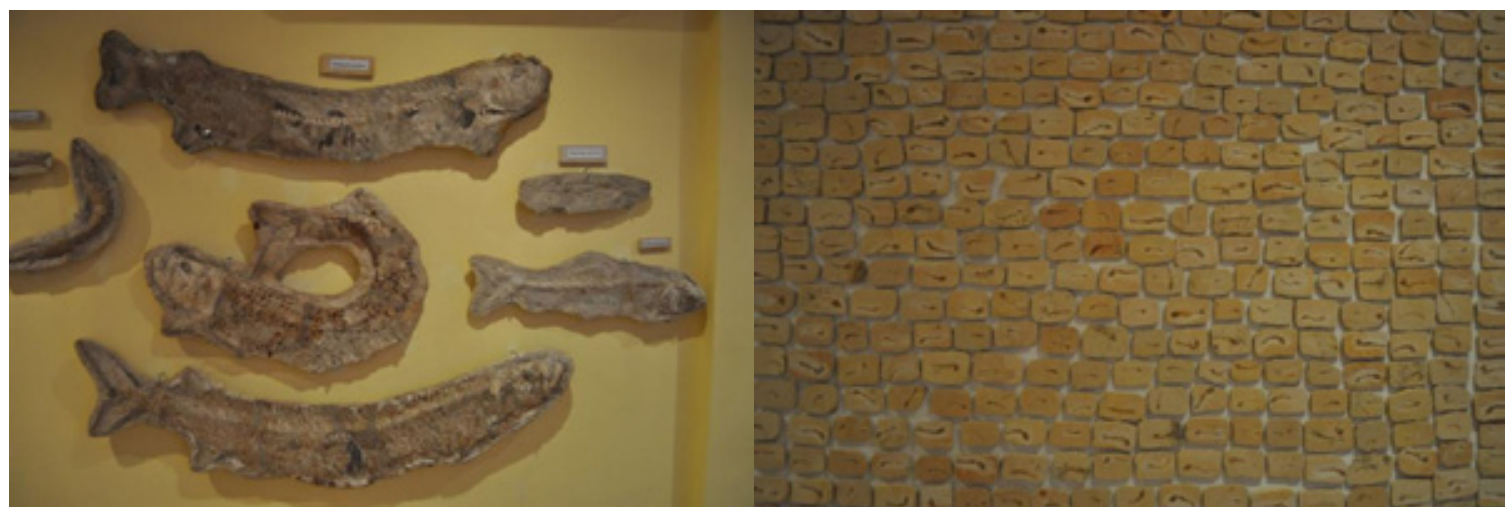

Fonte: os autores.

Figura 8: Imagem do holótipo da Cratoavis cearense, encontrado na região. Pela primeira vez, um esqueleto articulado e quase completo de uma ave do Cretáceo Inferior da América do Sul foi documentado (2014).

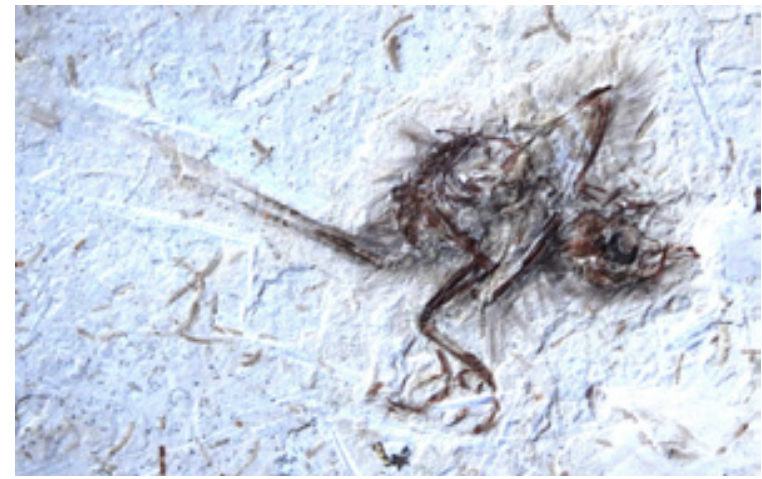

Fonte: os autores.

Figura 9: Imagem de um vegetal fóssil encontrado na Bacia do Araripe. A qualidade da preservação é um destaque, preservando partes delicadas como as folhas dos espécimes vegetais (2014).

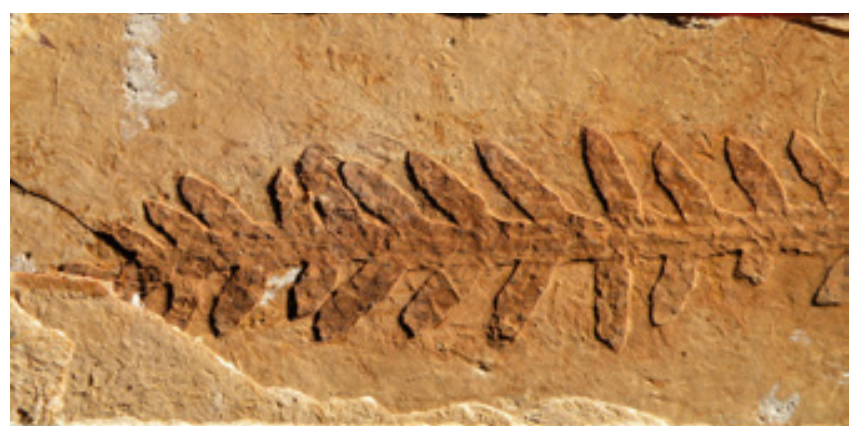

Fonte: os autores.

Diante da incontestável importância científica, há o contexto socioeconômico do local, que apresenta profundos problemas para sobrevivência digna de sua população. Dados do Programa das Nações Unidas para o Desenvolvimento (PNUD) revelam que o município de Santana do Cariri possui o Índice de Desenvolvimento Humano (IDH) mais baixo de todos os municípios que integram o Geopark Araripe. Os dados de 2010 mostram que o município ocupa a $3.866^{a}$ posição no ranking nacional (PNUD-BRASIL, 2010). 
A questão escolar ainda é um desafio a ser enfrentado pelo município. Há apenas uma escola pública estadual, responsável pelo Ensino Médio. Os moradores de todos os distritos deslocam-se para a Sede para estudar, através de um escasso sistema de transporte privado, como motocicletas, topiques (vans) ou a pé. Para cursar uma universidade, é necessário se dirigir a outro município, atravessando a Chapada do Araripe, para estudar no Crato ou em Juazeiro do Norte, a $55 \mathrm{~km}$ e $66 \mathrm{~km}$ de distância, respectivamente (CASTRO, 2014).

A maior parte da fonte de renda local é proveniente do trabalho informal, onde as atividades de pedreiro ou de dona de casa ocorrem simultaneamente com a de lavrador (um trabalho sazonal e muito comum no município), cujo ofício representa uma complementação na renda familiar através da agricultura de subsistência. Os aposentados e pensionistas também possuem uma importância para a economia local, assim como os funcionários da administração municipal. Como muitos estão insatisfeitos, seja pela pequena oportunidade de estudo ou de trabalho, há uma intensa emigração para outras regiões do país, em especial dos mais jovens em busca de melhores condições de vida (CASTRO, 2014).

Figura 10: A renda e/ou alimentação de uma parte considerável da população de santanense é proveniente da agricultura. À esquerda, o manejo da vagem para retirada dos grãos e à direita, os grãos coletados secam ao sol na frente de casa (2012).
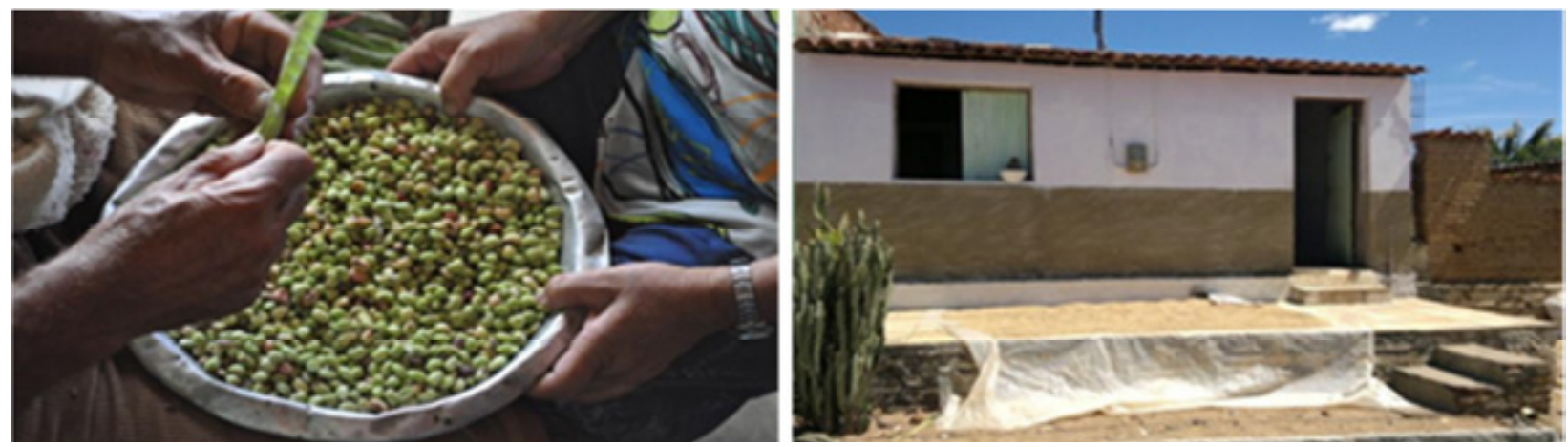

Fonte: os autores.

Figura 11: Trabalhadores atuando na extração do calcário laminado para comercialização e utilização na construção civil, outra importante fonte de renda na região (2011).
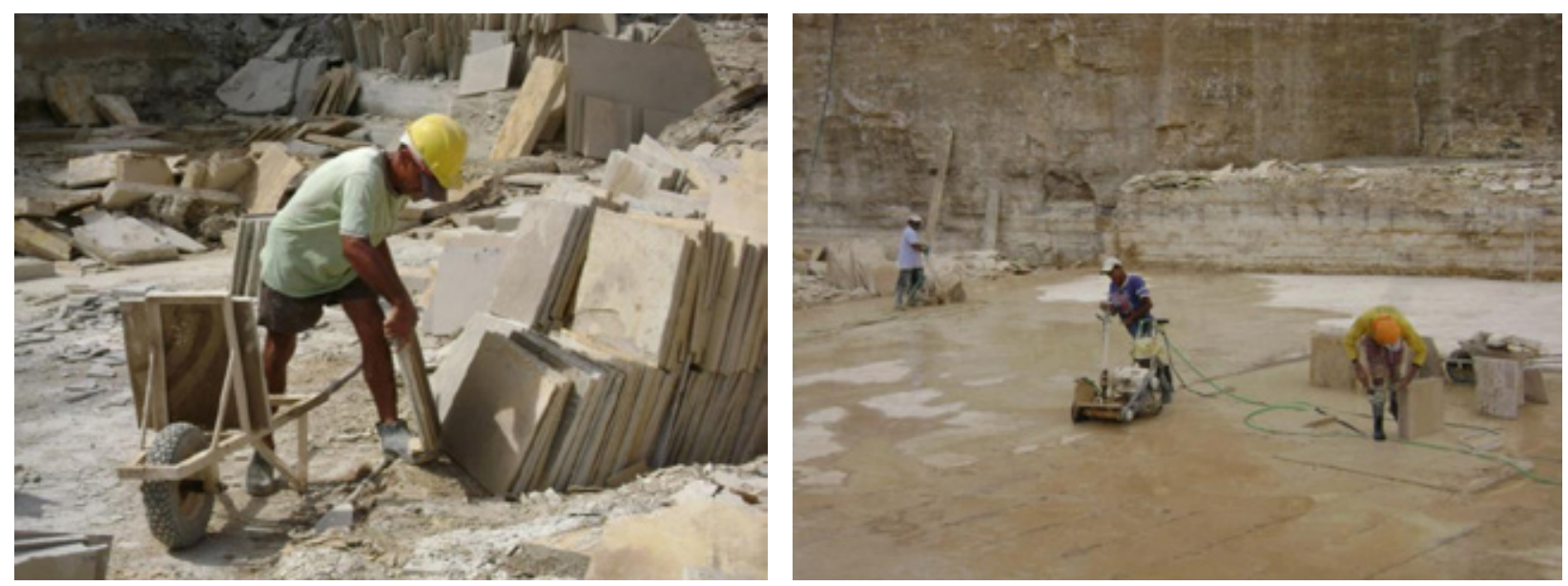

Fonte: os autores. 
Esse contexto torna compreensível, na prática, o papel fundamental do Geopark Araripe na área. Ele representa uma possibilidade de melhoria da qualidade de vida, inclusive aos olhos da população local e isso está relacionado à compreensão do patrimônio de forma integral. Como muitos não estão satisfeitos com a situação socioeconômica do município, para eles, o geoparque oportuniza a esperança de um futuro melhor. A valorização da geodiversidade, a geoconservação e o geoturismo pode ser compreendida como uma forma de beneficiar um local pouco desenvolvido economicamente (ou mesmo outro que já seja economicamente estruturado e sustentável ${ }^{5}$ ) (CASTRO, 2014).

Para além da discussão econômica, há também uma relação de afeto com a cidade, pois muitos santanenses retornam à cidade, por diversos motivos, mas é possível inferir que relações cotidianas com a geodiversidade presente contribua para o fortalecimento do sentimento de pertença e identidade àquela comunidade. Pode-se afirmar isso porque a população se relaciona com a geodiversidade local e orgulha-se dela. Falam empoderados da beleza do Pontal da Santa Cruz e das lendas e histórias que o permeiam, da paisagem santanense moldada pela Chapada do Araripe, da dinâmica e técnicas de extração das rochas, da água potável abundante na região em meio ao sertão e do trabalho com a terra que exige manejo e garante o sustento (CASTRO, 2014).

Os fósseis também são motivos de orgulho, pois antes mesmo da intervenção científica, a população já havia percebido a sua relevância, utilizando-os em brincadeiras ou para decorar suas casas, pois esses 'objetos' se diferenciavam dos demais. O comércio de fósseis se iniciou com a intervenção da comunidade científica que, ao valorizar aquelas peculiares formas como patrimônio, também agregou a elas, de forma paralela e não intencional, um valor de mercado.

Neste cenário, onde belos e raros exemplares de geodiversidade se mesclam com uma realidade social complexa, cria-se uma esfera de tensão, pois são múltiplos os olhares para o mesmo elemento. Isso ocorre porque a relevância da diversidade geológica que aflora neste local não se dá somente através do culto à exuberância cênica e à importância científica, mas também em função das relações que as pessoas travam com ele, tanto de forma positiva, quanto negativa. Assim, o patrimônio (geológico) existente no município de Santana do Cariri, Ceará, é múltiplo e, por isso, científico, histórico, ambíguo, subjetivo, tangível, intangível, político e dinâmico, em constante relação com os que dele se apropriam.

5 De forma diversa, no Sul do Brasil, região economicamente mais estável, com uma comunidade mais organizada em torno do agronegócio, uma proposta de criação de geoparque não despertou interesse por parte dos ruralistas por confundirem as restrições que ocorrem aos Parques Nacionais (do Sistema Nacional de Unidades de Conservação) com as que poderiam ocorrer em um Geoparque devido à similaridade na grafia (GUIMARÃES et al., 2012). No entanto, deve-se considerar que um geoparque tem lugar em ambas as situações e pode contribuir ressaltando a importância geológica, de forma associada ao desenvolvimento cultural, econômico e social das regiões. Nesse caso, um geoparque poderá contribuir ao ampliar e diversificar as suas possibilidades de investimento, incentivando as atividades geoturísticas e a produção de geoprodutos, além das atividades educativas junto à comunidade (CASTRO, 2014). 


\section{CONSIDERAÇÕES FINAIS}

Nesse trabalho foi possível refletir sobre as diversificadas formas de apropriação de uma população sobre a geodiversidade. Esses elementos podem, dependendo da conceituação adotada, não serem reconhecidos como um patrimônio apenas por possuírem um valor científico baixo. No entanto, isto poderia ser diferente se fossem avaliados segundo uma abordagem mais abrangente do que seja patrimônio, sem complementos ou adjetivações e, mais especificamente, do que seja o patrimônio em sentido integral. Ele pode estar presente nas ações cotidianas e fazer parte da identidade daquele território, numa dinâmica própria de relações sociais e patrimoniais.

Ao observar a dinâmica social existente em Santana do Cariri, percebe-se o conflito da geodiversidade mesclada com as atividades cotidianas e econômicas locais, dificultando sua percepção pela população como um patrimônio científico. Isso ocorre porque, na maior parte das vezes, a geodiversidade foi valorizada como patrimônio apenas pelo 'outro', ou seja, por cientistas que, em sua maior parte, residem em outras regiões do país ou no exterior e acabam por determinar (direta ou indiretamente) o que é importante ou não para aquela comunidade.

Compreender esse processo como um todo é necessário para se desenvolver ações de comunicação científica ${ }^{6}$ efetivas, inspiradas na metodologia da educação patrimonial, sem considerar apenas a perspectiva científica ou legalista aplicada a regiões como neste estudo de caso, onde ainda ocorre, de forma pontual, o comércio ilegal de fósseis. A geodiversidade deve ser trabalhada como parte integrante da identidade local, valorizando todas as relações existentes entre ela e o cotidiano social, presente na agricultura de subsistência, na extração das rochas, água, relevo e até mesmo através da culinária, da religiosidade e das danças.

Por isso, é necessário que as iniciativas patrimoniais considerem também o seu papel como mecanismo de transformação social. Se, por meio do geoturismo participativo, esses elementos passarem a gerar recursos financeiros para todos, a sua percepção patrimonial levará à valorização da geodiversidade local e sua conservação.

As análises feitas a partir da realidade de Santana do Cariri, Ceará, dão subsídios importantes para definir, valorizar e gerir o patrimônio geológico à luz de conceitos que vêm sendo aprimorados ao longo de décadas. No entanto, para que isso ocorra, é importante olhar para a parcela da sociedade que não é especialista. Essa compreensão necessita de diálogo, que nem sempre será harmônico, pois envolve uma disputa por espaço, saberes e poder. Mas há lugar para todos nessa discussão, pois não existe apenas um grupo que seja guardião do conhecimento ou de um patrimônio. Outras esferas da sociedade desejam se apropriar e, quando há a compreensão de que a geodiversidade pode ser patrimônio, há abertura para o envolvimento social.

Os especialistas que atribuem os valores são os mais variados e podem ser representantes das mais diversas profissões e até mesmo serem lideranças comunitárias, que

6 Para aprofundamento nas reflexões entre divulgação, educação e comunicação científica, ver Samagaia (2016). 
possuem a função de representar e expressar o desejo da sociedade. Todos possuem o direito de identificar e usufruir de um patrimônio, por isso, as formas de proteção também devem se diversificar, ampliando as possibilidades de atuação da geoconservação.

Assim, se formos instados a conceituar patrimônio geológico, ou seja, se for necessário adjetivar o substantivo, seria adequado delimitar a definição segundo a discussão sobre a qual o conceito se conformou: exemplares da geodiversidade, in situ ou ex situ, que tenham valor científico, educativo, turístico ou outro, atribuído por especialistas, acadêmicos ou não, e que necessitam ser protegidos e apropriados por esta e pelas futuras gerações.

Através deste panorama sobre a dinâmica patrimonial no município de Santana do Cariri, espera-se contribuir para ampliar as possibilidades de atuação e apropriação do patrimônio geológico e subsidiar a criação de novas estratégias de educação e de preservação do patrimônio geológico, realizadas em sentido integral.

\section{REFERÊNCIAS}

ARAI, M.; COIMBRA, J.C. Análise paleoecológica do registro das primeiras ingressões marinhas na Formação Santana (Cretáceo Inferior da Chapada do Araripe). In: SIMPÓSIO SOBRE A BACIA DO ARARIPE E BACIAS INTERIORES DO NORDESTE, 1, 1990, Crato. Anais ... p. 225-240.

ASSINE, M.L. Bacia do Araripe. Bol. Geoc. Petrobras, Rio de Janeiro, v. 15, n. 2, p. 371-389, 2007.

BABELON, J.P.; CHASTEL, A. La Notion de patrimoinie. Paris: Liana Levi, 1994. 141p.

BARRAU, J. Fóssil. In: Memória - História. Enciclopédia Einaudi. Imprensa Nacional, 1984. v.1, p. 87-94.

BEZERRA, R. de C. L. et al. Educação ambiental: edição para professores e gestores. Conselho de Políticas e Gestão do Meio Ambiente. Fortaleza: URC, 2010. 146p.

BRILHA, J.B.R. Patrimônio Geológico e Geoconservação: a conservação da natureza em sua vertente geológica. Viseu: Palimage, 2005. 190p.

. Inventory and Quantitative Assessment of Geosites and Geodiversity Sites: a Review. Geoheritage, v. 8, n. 2, p. 119-134, 2016.

BROSSARD, D.; LEWENSTEIN, B.V. A Critical Appraisal of Models of Public Understanding of Science Using Practice to Inform Theory. In: KAHLOR, L. A.; STOUT, P. (Eds). Communicating Science: New Agendas in Communication. Routledge, 2010. p. 11-39.

BRUNO, A. P. dos S.; HESSEL, M.H. Registros paleontológicos do cretáceo marinho na Bacia do Araripe. Estudos Geológicos, v. 16, n.1, p. 30-49, 2006.

CANCLINI, N.G. Culturas híbridas: estratégias para entrar e sair da modernidade. 2.ed. São Paulo: Ed. USP, 1998. 392p.

CARCAVILLA URQUÍ, L.; LÓPEZ MARTÍNEZ, J.; DURÁN VALSERO, J.J. Patrimonio geológico y geodiversidad: investigación, conservación, gestión y relación con los espacios naturales protegidos. Madrid: Instituto Geológico y Minero de España, 2007. (Cuadernos del Museo Geominero, 7).

CARVALHO, I. de S.; MELO, J.H.G. de. Bacias Interiores do Nordeste. In: HASUI, Y.; CARNEIRO, C.D.R.; ALMEIDA, F.F.M. de; BARTORELLI, A. (Orgs.). Geologia do Brasil. São Paulo: Beca, 2012. p. 502-509.

CARVALHO, L.M. de; SCHEINER, T. Construindo o "discurso" do Patrimônio: das organizações internacionais e institutos nacionais a uma relação profunda entre o homem e o patrimônio - o caso do Marolo, em Paraguaçu, Minas Gerais. In: SEMINÁRIO DE INVESTIGAÇÃO EM MUSEOLOGIA DOS PAÍSES DE LÍNGUA PORTUGUESA E ESPANHOLA, 2, 2010, Buenos Aires. [s.p.].

CARVALHO, M. de. O que é Natureza. São Paulo: Brasiliense, 1999. 89p. (Primeiros Passos). 
CARVALHO, M.S.S. de; SANTOS, M.E.C.M. Histórico das Pesquisas Paleontológicas na Bacia do Araripe, Nordeste do Brasil. An. Inst. Geoc., Rio de Janeiro, v.28, n.1, p.15-34, 2005.

CASTRO, A.R. de S.F. de. O patrimônio geológico sob a perspectiva da população residente no município de Santana do Cariri, Ceará. Rio de Janeiro, 2014. 301f. Tese (Doutorado em Geologia) - Universidade Federal do Rio de Janeiro, UFRJ.

. Reflexões sobre a compreensão da geodiversidade como patrimônio. In: SIMPÓSIO BRASILEIRO DE PATRIMÔNIOGEOLÓGICO/ ENCONTROLUSO-BRASILEIRODEPATRIMÔNIOGEOMORFOLÓGICO E GEOCONSERVAÇÃO, 4/2, 2017, Ponta Grossa. Anais... p. 674-677. Disponível em: https:/ / www.4sbpg. com/anais Acesso em: 14 abr. 2018.

;MANSUR, K.L.; CARVALHO, I.S. Diagnóstico da relação da comunidade com o patrimônio geológico por meio de instrumento de coleta de dados. Terræ Didatica, v. 11, n. 3, p.162-172, 2015. Disponível em: http:/ / www.ige.unicamp.br/terraedidatica/ Acesso em: 14 abr. 2018.

CHAGAS, M. de S. Casas e portas da memória e do patrimônio. Em questão, Porto Alegre, v.13, n.2. p.20724, jun./dez. 2007.

CHOAY, F. A alegoria do patrimônio. São Paulo: Ed. UNESP, 2001. 284p.

CPRM. SERVIÇO GEOLÓGICO DO BRASIL. Mapa Geodiversidade do Brasil 1:2.500.000. Sistema de Informações Geográficas. Brasília, 2006. 68p. CD-ROM.

GARCÍA-CORTÉZ, A.G.; CARCAVILLA, L.U. Propuesta para laactualización metodológica del Inventario Español de Lugares de Interés Geológico (IELIG).Versión 11. Madrid: Instituto Geológico y Minero de España, 2009. 61p.

GONÇALVES, J.R.S. A Retórica da Perda: os discursos do patrimônio cultural no Brasil. 2.ed. Rio de Janeiro: UFRJ/IPHAN, 2002. 147p.

GORDON, J.E.; LEYS, K.F. Earth Science and the Natural Heritage: Developing a More Holistic Approach. In: ___ _ Earth Science and the Natural Heritage: Interactions and Integrated Management. Edinburgh: Scottish Natural Heritage, 2001. p.5-18.

GRAY, M. Geodiversity: valuing and conserving abiotic nature. London: John Wiley \& Sons, 2004. 434p.

Geodiversity: The origin and evolution of a paradigm. In: BUREK, C.; PROSSER, C.D. The history of Geoconservation. London: The Geological Society of London, 2008. 312p. (Geological Society Special Publication, 300).

Geodiversity: valuing and conserving abiotic nature. London: John Wiley \& Sons, 2013. 508p.

GUIMARÃES, G.B. et al. Geoparque dos Campos Gerais, PR: Por que ele ainda não foi criado? In: CONGRESSO BRASILEIRO DE GEOLOGIA, 46, 2012, Santos. Anais... [s.p.].

HAZEN, R.M. et al. On the mineralogy of the "Anthropocene Epoch". American Mineralogist, n. 102, p. 595-611, 2017.

HERZOG, A.L.; SALES, A.M.F.; HILLMER, G. The UNESCO Araripe Geopark: a short story of the evolution of life, rocks and continents. Fortaleza: Expressão Gráfica e Editora, 2008. 80p.

ICOM. Declaração de Santiago. Mesa Redonda de Santiago do Chile. 1972. In: PRIMO, J. Museologia e Patrimônio: Documentos Fundamentais - Organização e Apresentação. Cadernos de Sociomuseologia, n.15, p.95-104, 1999.

KIERNAN, K. Landform Conservantion and Protection. In: REGIONAL SEMINAR ON NATIONAL PARKS AND WILDLIFE MANAGEMENT, 5, 1991, Hobart. Resource Document, p. 112-129.

KOZLOWSKI, S. Geodiversity. The concept and scope of geodiversity. Przeglad Geollogiczny, v. 52, n. 8/2, p. 833-837, 2004. Disponível em: <https://www.pgi.gov.pl/images/stories/przeglad/pdf/ pg_2004_08_2_22a.pdf> Acesso em: 02 maio 2018.

KUNZLER, J.; MACHADO, D.M.C. O “discurso oficial” sobre o fóssil como patrimônio. In: SIMPÓSIO BRASILEIRO DE PATRIMÔNIO GEOLÓGICO/ ENCONTRO LUSO-BRASILEIRO DE PATRIMÔNIO 
GEOMORFOLÓGICO E GEOCONSERVAÇÃO, 4/2, 2017, Ponta Grossa. Anais ... p. 669-673. Disponível em: https://www.4sbpg.com/anais Acesso em: 14 abr. 2018.

LEWENSTEIN, B.V. Models of Public Communication of Science \& Technology. Public Understanding of Science, Version 16, 2010. 11p. Disponível em: < https://edisciplinas.usp.br/pluginfile.php/43775/ mod_resource/content/1/Texto/Lewenstein\%202003.pdf> Acesso em: 14 abr. 2018.

LIMA, D.F.C. Social Memory and Museum Institution: Thinking about the (re)presentation of Cultural Heritage. In: ANNUAL CONFERENCE OF ICOFOM/INTERNATIONAL COMITEE FOR MUSEOLOGY, 19, 1997, Paris. Anais... p. 202-211.

; COSTA, I.R. Ciência da Informação e Museologia: estudo teórico de termos e conceitos em diferentes contextos - subsídio à linguagem documentária. In: ENCONTRO NACIONAL DE ENSINO E PESQUISA DA INFORMAÇÃO, 7, 2007, Salvador. Anais ... Disponível em http:/ /www.cinform.ufba.br/7cinform/ soac/papers/adicionais/DianaLima.pdf Acesso em: 20 dez. 2017.

MARTILL, D.M.; BECHLY, G.; LOVERIDGE, R.F. (Orgs.). The Crato Fossil Beds of Brazil: Window into an Ancient World. Cambridge: Cambridge University Press, 2007. 625p.

MASSARANI, L.; MOREIRA, I.C.; BRITO, F. Ciência e Público: caminhos da divulgação científica no Brasil. Rio de Janeiro: Casa da Ciência/UFRJ, 2002. 232p. (Terra Incógnita, 1).

MODICA, R. As redes europeia e global dos Geoparques (EGN e GGN): proteção do patrimônio geológico, oportunidade de desenvolvimento local e colaboração entre territórios. Geol. USP, São Paulo, v. 5, p. 17-26, 2009.

MOURA, G.J.B.; BARRETO, A.M.F.; BÁEZ, A.M. A biota da Formação Crato, Eocretáceo da Bacia do Araripe, Nordeste do Brasil. Olinda: Elógica, 2006. 100p.

NASCIMENTO, M.A.L.; RUCHKYS, U.A.; MANTESSO NETO, V. Geodiversidade, geoconservação e geoturismo: trinômio importante para a proteção do patrimônio geológico. São Paulo: SBGEO, 2008. 82p.

PAES-LUCHIARI, M.T.D.; BRUHNS, H.T.; SERRANO, C. (Orgs.). Patrimônio, Natureza e Cultura. Campinas: Papirus, 2007. 176p.

PEREIRA, P. Património geomorfológico: conceptualização, avaliação e divulgação: aplicação ao Parque Natural de Montesinho. Minho, 2006. 370f. Tese (Doutorado em Ciências) - Universidade do Minho.

PNUD-BRASIL. Ranking IDHM Municípios 2010. Disponível em: http://www.pnud.org.br/ atlas/ ranking/Ranking-IDHM-Municipios-2010.aspx Acesso em: 12 fev. 2014.

PONCIANO, L.C. et al. Patrimônio geológico-paleontológico in situ e ex situ: definições, vantagens, desvantagens e estratégias de conservação. In: CARVALHO, I. deS.;SRIVASTAVA, N. K.;STROHSCHOEN JR., O.; LANA, C.C. (Org.). Paleontologia: cenários de vida. Rio de Janeiro: Interciência, 2011. v. 4, p. 853871.

SAMAGAIA, R.R. Comunicação, divulgação e educação científicas: Uma análise em função dos modelos teóricos e pedagógicos. Florianópolis, 2016. 352 f. Tese (Doutorado em Educação Científica e Tecnológica) - Universidade Federal de Santa Catarina, UFSC.

SANTOS, D.S. et al. Quantitative assessment of geodiversity and urban growth impacts in Armação dos Búzios, Rio de Janeiro, Brazil. Applied Geography, v. 85, p.184-195, 2017.

SANTOS, R. da S. Fósseis do Nordeste do Brasil: Paleoictiofáunula da Chapada do Araripe. Rio de Janeiro: UERJ, 1991. 61p.

SCHEINER, T.C.M. Imagens do "não lugar": comunicação e os novos patrimônios. Rio de Janeiro, 2004. 292f. Tese (Doutorado em Comunicação) - Universidade Federal do Estado do Rio de Janeiro, UFRJ.

. Sob o signo do patrimônio: museologia e identidades regionais. In: COSTA, H.; DECAROLIS, N.; SCHEINER, T. (Coords.) Museologia e o Patrimônio Regional: Encontro do Subcomitê Regional do ICOFOM para a América Latina e o Caribe (12) - Salvador, Bahia, Brasil. 08/12 dezembro 2003. Rio de Janeiro: Tacnet Cultural, 2006.

SHARPLES, C. Concepts and principles of geoconservation. Tasmania: Parks \& Wildlife Service, 2002. 
81p. Disponível em: http://www.dpiw.tas.gov.au/inter.nsf/Attachments/SJON-57W3YM/\$FILE/ geoconservation.pdf Acesso em: 20 dez. 2017.

SOUZA, A.R. de. Geoconservação e musealização: a aproximação entre duas visões de mundo, os múltiplos olhares para um patrimônio. Rio de Janeiro, 2008. Dissertação (Mestrado em Museologia e Patrimônio) Universidade Federal do Estado do Rio de Janeiro, UFRJ.

; MIRANDA, M. A produção científica acerca do patrimônio geológico: análise das referências bibliográficas brasileiras e portuguesas. In: ENCONTRO NACIONAL DE PESQUISA EM CIÊNCIA DA INFORMAÇÃO, 8, 2007, Salvador. Anais... p.11.

STANLEY, M. Geodiversity. Earth Heritage, v.14, p. 15-18, 2000. Disponível em: http:/ / www.earthheritage. org.uk/ehpdf/EH14-2000.pdf . Acesso em: 12 abr. 2017.

UCEDA, A.C. El Património Geológico. Ideas para su proyección, conservación y utilización. In: MOPTIMA (Ministerio de obras públicas, transportes y medio ambiente). El patrimonio geológico: bases para su valoración, protección, conservación y utilización. Madrid, 1996. p. 17-28. (Serie monografías).

Património geológico; diagnóstico, clasificación y valoración. In: SUÁREZ-VALGRANDE, J.P. (Coord.). Jornadas sobre Património Geológico y Desarrollo Sostenible: Soria, 22-24 Septiembre 1999. Madrid: Ministério de Medio Ambiente, 2000, p.23-37. (Monografías).

UNESCO. Convenção sobre a Proteção do Patrimônio Mundial, Cultural e Natural de 16 de novembro de 1972. 1972. In: CURY, I. (Org.). Cartas Patrimoniais. 2.ed. rev. aum. Rio de Janeiro: IPHAN, 2000. p. 177193.

VIANA, M.S.S. 164 anos de pesquisas paleontológicas na Chapada do Araripe: Formação Santana (Cretáceo Inferior). In: DNPM. Atas dos Simpósios sobre a bacia do Araripe e bacias interiores do nordeste realizados em Junho de 1990 e Novembro de 1997. Crato, 2001. p.195-211.

; NEUMANN, V.H.L. O Membro Crato da Formação Santana, Chapada do Araripe, Ceará: riquíssimo registro da fauna e flora do Cretaceo. In: SCHOBBENHAUS, C. et al. Sítios Geológicos e Paleontológicos do Brasil (SIGEP). Brasília: DNPM, 2002. p. 113-120.

ZANIRATO, S. H.; RIBEIRO, W. C. Patrimônio cultural:a percepção da natureza como um bem não renovável. Rev. Bras. Hist., São Paulo: v. 26, n. 51, p. 251-262, jun. 2006.

\section{AGRADECIMENTOS}

A pesquisa foi apoiada pela Fundação Carlos Chagas Filho de Amparo à Pesquisa do Estado do Rio de Janeiro (FAPERJ) e Conselho Nacional de Desenvolvimento Científico e Tecnológico (CNPq). Os autores também agradecem à comunidade santanese, em especial, a Ypsilon Félix, a Francisco Idalécio de Freitas, a Paula Nuvens e ao Museu de Paleontologia de Santana do Cariri (URCA) pelo apoio em Santana do Cariri.

Data de submissão: 07/maio/2018

Data de aceite: 07/jul./2018 